\title{
HIJRAH ISLAMI MILENIAL BERDASARKAN PARADIGMA BERORIENTASI IDENTITAS
}

\author{
Suci Wahyu Fajriani ${ }^{1}$, Yogi Suprayogi Sugandi ${ }^{2}$ \\ ${ }^{1}$ Mahasiswa Magister Program Studi Sosiologi, Universitas Padjadjaran, Indonesia \\ suci18011@mail.unpad.ac.id
}

\begin{abstract}
ABSTRAK
Tujuan penelitian adalah mendeskripsikan perkembangan hijrah islami milenial, dengan mencerminkan perubahan diri ke arah yang lebih baik berlandaskan ajaran agama Islam. Metode penelitian menggunakan pendekatan studi kepustakaan dengan mengumpulkan informasi dari jurnal, buku, dokumen elektronik, dan berita online. Hijrah Islami menjadi gerakan sosial baru di masyarakat, paradigma berorientasi identitas sebagai analisis penelitian, karena menitikberatkan pada keterlibatan para aktor dan aksi kolektif. Analisis dikaji dengan lima kelebihan paradigma berorientasi identitas dalam menganalisis gerakan sosial hijrah, hasilnya adalah: (1) Gerakan hijrah dilihat pada banyaknya public figure perempuan yang beragama Islam menggunakan hijab serta para artis yang mengikuti kegiatan kajian, pelaku ekonomi di bidang pakaian muslim meningkat dalam memproduksi baju-baju muslim dan muslimah, peran media social dalam memberikan kajian tentang agama Islam; (2) Ekspresi hijrah islami milineal, terlihat pada gagasan yang maju, pola pikir lebih kritis dan terbuka sehingga dapat menilai mana perbuatan yang baik dan buruk; (3) Perilaku ekspresif dengan mengikuti berbagai kajiankajian islam di berbagai daerah yang membahas tentang agama Islam; (4) Peran dan posisi aktor milenial dalam melaksanakan hijrah yang berperan sebagai muslim dan muslimah sesuai dengan ajaran agama islam serta posisi actor sebagai manusia yang ingin mendapatkan makna dari hijrah Islami; (5) Menempatkan individu dalam hijrah islami ke arah tujuan hidup yang lebih baik dan terarah. Kesimpulan, hijrah islami merupakan gerakan sosial baru yang terjadi pada masyarakat milenial sebagai penguat identitas umat Islam berdasarkan ajaran agama Islam.
\end{abstract}

Kata kunci: Hijrah, islami, milenial dan identitas

\begin{abstract}
The purpose of this study is to describe the development of Islamic hijrah millennial, by reflecting selfchange towards a better direction based on the teaching of Islam, with identity oriented. The research method uses the library study approach by collecting information from journalsm books, electronic documents and online news. Islamic hijrah is becoming a new social movement in the community, an identity-oriented paradigm as a research analysis, because it focuses on the involvement of actors and collective action. The analysis assessed by five excess oriented paradigm of identity in analyzing social movements move, the result is: (1) Movement moved views on many public figures of women who are Muslims use the hijab as well as the artists who participated in the study, economic actors in the field of Muslim clothing increased in manufacturing clothes muslim, social media's role in providing the study of the Islamic religion; (2) The expression of Islamic Hijrah milineal, look at the idea advanced, more critical mindset and open so that it can assess which actions are good and bad; (3) Conduct expressive by attending various Islamic studies in various areas to discuss about Islam; (4) The role and position of the millennial actors in implementing the move which acts as a muslim in accordance with teachings of the religion of Islam and the position of the actor as a man who wants to get the meaning of Hijrah Islamic; (5) Putting individuals in Islamic move toward the goal of a better life and direction. In conclusion, the Islamic Hijrah is a new social movement that occurs in the millennial society as a reinforcement of Muslims based on the teachings of Islam.
\end{abstract}

Keywords: Hijrah, islamic, millennial, and identity

\footnotetext{
${ }^{2}$ Prodi Pascasarjana Sosiologi, Fakultas Ilmu Sosial dan Ilmu Politik, Universitas Padjadjaran yogi.suprayogi@unpad.ac.id
} 


\section{PENDAHULUAN}

Fenomena merupakan suatu hal yang terjadi di kalangan masyarakat yang biasanya memiliki dampak besar dan banyak individu-individu yang mengikutinya. Hijrah adalah berpindahnya suatu individu ataupun kelompok ke arah yang lebih baik. Dalam konteks Islam, hijrah diartikan sebagai berpindahnya individu ataupun kelompok ke arah yang lebih baik berdasarkan agama Islam. Fenomena hijrah islami banyak terjadi pada masyarakat milenial yang berkembang sangat besar di Indonesia, yang disebabkan oleh adanya keinginan individu atau kelompok untuk menjadi pribadi yang lebih baik lagi dari sisi agama Islam.

Berlandaskan sejarah hijrah, menurut ulama Syafi'i Al-Mawardi, setelah terjadi penaklukan Mekah oleh Nabi Muhammad dan teman-temannya, Hijrah menjadi kewajiban bagi orangorang muslim yang tidak dapat menjalankan agama mereka. Persepsi ini menyatakan bahwa pada zaman Nabi, pelaksanaan perintah dan tugas agama adalah tujuan utama hijrah (Uberman, Matan \& Shay, 2016). Peristiwa hijrah terlihat dari bagaimana Rasulullah saw membangun sosiokultural Islami di Madinah dengan melaksanakan Muakhat (mempersaudarakan) antara muhajirin dan kaum ansar (Nafsiyah, Amaliyah, Hijrah, \& Amaliyah, 2016). Berdasarkan ungkapan Muhammad As'ad, dosen Universitas Hasyim Asy'ari di Jawa Timur, mengungkapkan bahwa hijrah berubah arti menjadi makna budaya, individu yang menjauhi diri dari perilaku buruk agar memperoleh gaya hidup yang lebih islami. Keputusan berhijrah terjadi pada kalangan kelas menengah, khususnya mahasiswa karena berpendidikan dan secara ekonomi lebih kaya dibandingkan masyarakat desa, sehingga hijrah terjadi karena sudah popular di media sosial (Yuniar, 2019).

Kerja sama antara Tabah Foundation dari Uni Emirat Arab dengan Zogby Research Service melaksanakan survei yang besar mengenai pandangan generasi milenial muslim tentang peran agama. Sampel diambil dari beberapa negara di timur tengah diantaranya Maroko, Mesir, UEA, Arab Saudi, Yordania, Palestina, Bahrain, dan Kuwait. Hasil dari penelitian ditemukan bahwa seluruh negara setuju bahwa agama memiliki peran penting untuk masa depan negara. Persentase diperoleh sebanyak 100\% generasi milenial meyakini kebenaran agama Islam dari empat negara (Arab Saudi, Bahrain, Kuwait, Yordania). Sedangkan Mesir, UEA, dan Palestina (90\%), dan Maroko (77\%) (James, Elizabeth, \& Hope, 2015).

Muhammad Faisal dari Youth Labs melakukan riset yang tercantum pada buku "Generasi Phi: Memahami Milenial Pengubah Indonesia (2017)", riset pada kelompok anak muda dari berbagai daerah, hasil diperoleh bahwa jawaban tentang keagamaan dan ingin membahagiakan orang tua lebih dominan. Muhammad Najib Azca, seorang sosiolog dari Universitas Gajah Mada mengungkapkan bahwa terdapat pola-pola anak muda dalam fenomena hijrah, yaitu 


\section{Suci Wahyu Fajriani}

sebagai fenomena sosial yang krisis dialami manusia, tertutama anak muda. Krisis tersebut, manusia membutuhkan jawaban dengan menghasilkan perubahan indikator keagamaan. Selain itu, gaya hidup timur tengah berkembang, anak muda lebih mudah menerima hal baru dan mengalami perubahan. Menurutnya, hijrah menjadi cara hidup yang baru, manusia tidak hanya memikirkan keselamatan sendiri, namun juga keselamatan atau kesejahteraan dan keadilan sosial. Menurut Prof. HM Baharun, Guru Besar Sosiologi Agama Universitas Negeri Sunan Ampel, mengungkapkan bahwa faktor pendorong masyarakat milenial untuk hijrah adalah (1) Remaja merasa kekosongan jiwa yang menimbulkan kejenuhan dan ketidaktenangan walapun telah kehidupan mengiming-imingi kesenangan. (2) Remaja yang sudah berpikir kritis, didukung dengan akses informasi keagamaan yang luas memudahkan remaja milenial untuk berkembang (Raharjo, 2018).

Fenomena hijrah didukung dengan banyaknya kajian-kajian islami dengan ustadz dan ustadzah yang memiliki daya tarik bagi para jamaah seperti ustadz Abdul Somad, Hanan Ataqqi, Adi Hidayat, Khalid Basalamah, Aam Amiruddin, Mamah Dedeh dan sebagainya. Seperti Ustadz Abdul Somad yang dicirikan dengan sejuta viewers, Ustadz Adi Hidayat yang juga banyak berdakwah di media sosial, serta Ustadz Hanan Attaki berdakwah dengan sasaran anak muda, bahkan membuat gerakan "pemuda hijrah". Ketiga Ustadz tersebut menyampaikan kajian islami atau dakwah melalui media sosial yang dapat bertahan di zaman modern saat ini (Abdullah, 2018).

Penelitian Abraham Z. Z. \& Dewi A. S. H. (2018) hasil penelitian ditemukan bahwa (1) Generasi milenial mempunyai karakteristik out of the box dan selalu terhubung dengan internet yang berdampak dalam perubahan kultur dakwah di Indonesia. (2) Media sosial memberikan kontribusi positif, namun juga terdapat goresan yang menimbulkan reaksi, yaitu dengan mudah tersebar ujaran kebencia, ketidakinginan mencari sumber primer dan masalah menyeleksi kualitas pendakwah. (3) Mencermati generasi milenial yang memiliki ciri toleran, pluralis, serta dapat menghargai perbedaan dan keberagaman yang melahirkan peluang besar dalam perkembangan dakwah Islam moderat di Indonesia (Zulhazmi \& Hastuti, 2018).

Dari fenomena hijrah islami yang terjadi di masyarakat merupakan bagian dari gerakan sosial baru yang berdampak pada generasi milenial. Rumusan masalah adalah "Bagaimana cara hijrah islami milenial berdasarkan paradigma berorientasi identitas?", dalam menganalisis permasalahan tersebut, peneliti menggunakan teori gerakan sosial baru pada paradigma berorientasi identitas sebagai penunjang analisis utama yang dikaitkan dengan permasalahan, analisis yang berarti ada aktor atau masyarakat yang melakukan aksi hijrah secara bersamaan karena berbagai faktor dan tujuan.

79 | SQSIOGLLBAL : Jurnal Pemikiran dan Penelitian Sasiologi, Vol. 3, №. 2, Juni 2019 


\section{METODE PENELITIAN}

Pendekatan penelitian menggunakan studi kepustakaan yang mengumpulkan berbagai informasi dari buku referensi, hasil penelitian sebelumnya yang berguna untuk landasan teori mengenai masalah yang akan dikaji (Sarwono, 2006). Studi kepustakaan mempunyai teknik pengumpulan data dengan menelaah buku, literatur, catatan, dan berbagai laporan yang sesuai dengan masalah penelitian (Nazir, 1998). Objek yang menjadi kajian penelitian adalah masyarakat milenial yang melakukan aksi hijrah dengan mengikuti kajian-kajian agama Islam. Unit analisis yang digunakan adalah mencari data, mereduksi data, menyajikan data dan menganalisis data, serta menarik kesimpulan. Sumber data penelitian ini diperoleh dari buku, jurnal, dan internet sesuai dengan permasalahan penelitian, terdiri dari 15 jurnal, 3 buku/ebook, 2 dokumen elektronik, dan 2 berita online tentang hijrah islami milenial berdasarkan paradigma berorientasi identitas.

\section{KERANGKA TEORI/KONSEP}

\section{Gerakan Sosial Baru (Paradigma Berorientasi Identitas)}

Gerakan Sosial Baru (GSB) mempunyai gambaran baru mulai dari tampilan wajah gerakan baru yang timbul di masyarakat, tipe-tipe, bentuk serta model gerakan sosial. Gerakan sosial baru memfoukuskan perspektif studi pada tindakan rasional yang didalamnya terdapat pemaksaan-pemaksaan bersifat struktural. Sifat gerakan sosial dipengaruhi oleh konteks struktural yang berkembang pada masanya, sehingga bentuk dan model gerakan sosial mempunyai tipe-tipe dan rumusan yang bersifat makro di berbagai permasalahan yang terjadi (Rusmanto, 2018).

Gerakan Sosial Baru (GSB) memiliki berbagai paradigma, diantaranya (1) Paradigma Ketegangan Struktur (structural strain paradigm) merupakan bentuk-bentuk ketegangan dengan tingkat yang tinggi, lebih dari pengalaman individu. Ketegangan dipahami secara objektif sebagai kondisi yang eksis dan menggambarkan keadaan tegang pada aktor-aktor sosial yang berkonflik. (2) Paradigma Mobilisasi Sumber Daya (resource mobilization paradigm) merupakan tindakan-tindakan diambil berdasarkan rasional. (3) Paradigma Berorientasi Identitas merupakna perspektif pada peranan identitas yang melandasi semangat individu dalam suatu gerakan. Menurut Touraine tindakan social penting, karenan aksi yang dilakukan oleh individu dalam gerakan social merupakan upaya memproduksi dan mentransformasikan struktur dan tatanan sosial yang ada (Rusmanto, 2018). Menurut teori gerakan sosial seperti Castells dan Diani, gerakan sosial diwakili oleh sekelompok orang dengan identitas kolektif dan nilai-nilai bersama, dan terdiri dari jaringan formal dan informal (Yasin, N. A. Mohd \& Azman, 2019). 


\section{Suci Wahyu Fajriani}

Paradigma Berorientasi Identitas merupakan perspektif pada peranan identitas yang melandasi semangat individu dalam suatu gerakan, gerakan yang bersifat non materialistik tetapi berfokus pada perilaku ekspresif. Aksi-aksi yang dilakukan para partisipan sebagai manusia secara keseluruhan. Terdapat peluang umum bahwa gerakan berorientasi identitas dan aksi kolektif adalah ekspresi manusia dalam mencari identitas, otonomi, dan pengakuan. Tokoh yang mendukung paradigma ini salah satunya adalah Pizzorno dalam buku Political Exchange and Collective Identity in Industrial Conflict (1978), menurutnya Para aktor sosial dalam GSB mencari identitas dan pengakuan melalui aksi ekspresif, melalui tuntutan universalistik dan tak dapat ditawar. Partisipasi langsung para aktor pada rentang yang sama mengakui kolektivitas berarti hasilnya tuntutan mereka bisa dinegosiasikan dan karakter partisipasinya jadi terwakilkan dan lebih representasional (Rusmanto, 2018).

Kelebihan dari perspektif paradigma berorientasi identitas adalah melibatkan aktor dan aksi yang dilakukan oleh masyarakat dalam mencapai tujuan tertentu, sehingga lebih tepat dibandingkan menggunakan paradigma ketegangan struktur dan paradigma mobilisasi sumber daya, berikut kelebihan dari paradigma berorientasi identitas, yaitu:

1) Secara umum, mendeskripsikan sebagian eskpresi kuat dari gerakan sosial baru di masyarakat modern yang banyak mengalami perubahan dalam mengungkapkan sesuatu

2) Ekspresi tatanan gerakan sosial baru melalui pandangan kelas dan mengurangi batasan kondisi material

3) Perilaku ekspresif menjadi fokus perhatian

4) Secara substantif, peran dan posisi aktor-aktor modern bersama-sama berjuang dengan sadar dalam memerangi kekuasaan sosial dalam menciptakan identitas baru dan ruang demokratis aksi sosial yang lebih bebas

5) Secara khusus, gerakan sosial baru meletakkan posisi pribadi sebagai kebersamaan yang bebas, manusia bebas dalam mengubah identitas dan mencari makna baru bagi identitasnya. (Rusmanto, 2018)

Paradigma berorientasi identitas dalam gerakan sosial baru (GSB) menitikberatkan pada keterlibatan para aktor dan aksi kolektif, yang keduanya memiliki hubungan timbal balik dalam melahirkan tindakan baru. Aktor yang berarti sebagai masyarakat yang melaksanakan gerakan sosial baru dan aksi kolektif berarti tindakan yang dilakukan secara bersama-sama dengan tujuan yang sama. 


\section{Hijrah}

Secara Etimologi, hijrah merupakan berpindahnya seseorang dari suatu tempat ke tempat yang lain dengan tujuan kebaikan. Dalam Al-Qur'an, hijrah mempunyai makna yang beragam, diantaranya:

a. Hijrah hati adalah mencela sesuatu yang benar karena takabur

b. Hijrah adalah berpindah dari satu tempat ke tempat yang lain untuk mencari keselamatan diri dan mempertahankan aqidah

c. Hijrah berarti pisah ranjang antara suami dan istri

d. Hijrah berarti mengisolir diri

(Ghufron, 2017)

Aspek-aspek hijrah, yaitu:

1. Segala sesuatu yang harus dihindarkan

2. Segala sesuatu yang harus ditegakkan

3. Segala sesuatu yang harus dijalankan secara konsisten dan tidak keluar dari batasan yang telah ditentukan

Secara operasional hijrah merupakan upaya meninggalkan segala kesulitan menjadi berbagai kemudahan, yang tidak keluar dari ketentuan yang telah ditetapkan oleh syariat, secara lahiriah maupun batiniah. Makna lain, hijrah sebagai usaha menjauhkan diri dari berbagai bentuk penyimpangan menuju tata aturan yang benar dan konsisten. Secara historis, hijrah merupakan tindakan pragmatis monumentalis yang bermakna nilai-nilai normative (Aswadi, 2011). Hijrah merupakan gerakan yang dilaksanakan oleh individu maupun kelompok dengan tujuan ke arah yang lebih baik. Kata hijrah tidak asing dalam masyarakat muslim, karena memiliki makna perubahan diri menjadi pribadi yang lebih islami sesuai dengan ajaran-ajaran agama Islam.

\section{Islami}

Secara terminologis, Islam merupakan agama wahyu dengan makna tauhid atau kesesaan Tuhan yang diturunkan oleh Allah SWT kepada Nabi Muhammad Saw sebagai utusan Allah yang terakhir dan berlaku bagi semua manusia dimanapun, kapan pun, dengan ajaran tentang kehidupan manusia. Menyampaikan wahyu kepada seluruh manusia tentang keyakinan dan ketentuan dalam menjalani kehidupan dan hubungan dengan Allah Swt., sesama manusia, dan alam lainnya. Bersumber dari Al-Qur'an yang bertujuan untuk memperoleh keridhoan Allah, rahmat, kebahagiaan dunia dan akhirat, dengan menerangkan akidah, syariat, dan akhlak (Jamal, 2011). 
Islam bermakna secara bahasa, diantaranya:

a) Al-Istislam, berarti berserah diri

b) Saliim berarti suci bersih secara fisik, akhlaq, pikiran, dan sebagainya. Bermakna bahwa yang beragamam Islam memiliki hati yang bersih (qalbun salim) saat beribadah keapada Allah swt

c) Salaam, berarti selamat atau sejahtera

d) Al-Salm, berarti perdamaian yang terkandung dalam surat Muhammad ayat 35

e) Sullam, berarti tangga yang terkandung dalam surat At-Tur ayat 38

f) Al-Silmu, ada beberapa penafsiran yang terkandung dalam makna ini, salah satunya yaitu bermakna umat muslim harus menjalankan ajaran agama Islam

(Jamal, 2011)

\section{Milenial}

Sejarah milenial pertama kali dicetuskan oleh William Strauss dan Neil dalam bukunya yangberjudul Millennials Rising: The Next Great Generation (2000). Istilah ini diciptakan pada tahun 1987, ketika anak-anak yang lahir pada tahun 1982 masuk pra-sekolah. Saat itu media mulai menyebut sebagai kelompok yang terhubung ke millennium baru di saat SMA di tahun 2000. Selain pendapat tersebut, pendapat lain oleh Elwood Carlson dalam bukunya yang berjudul The Lucky Few: Between the Greatest Generation and the Baby Boom (2008), generasi milenial adalah mereka yang lahir dalam rentang tahun 1983 sampai dengan 2001. Sedangkan Hasanuddin Ali dan Lilik Purwandi (2017) dalam bukunya Millennial Nusantara menyebutkan bahwa Generasi milenial adalah mereka yang lahir antara tahun 1981 sampai dengan tahun 2000 (Budiati, 2018). Manheim mendefinisikan generasi adalah suatu konstruksi sosial yang di dalamnya terdapat sekelompok orang yang memiliki kesamaan umur dan pengalaman historis yang sama. Dalam penelitian Kupperschmidt (2000) generasi adalah sekelompok individu yang mengidentifikasi kelompoknya berdasarkan kesamaan tahun kelahiran, umur, lokasi, dan kejadian-kejadian dalam kehidupan kelompok individu tersebut yang memiliki pengaruh signifikan dalam fase pertumbuhan mereka (Budiati, I., Susianto, Y., Adi, W., 2018).

\section{Ciri-ciri Generasi Milenial}

Generasi milenial memiliki ciri-ciri diantaranya, penggunaan komunikasi, media, dan teknologi digital semakin meningkat dan akrab; kualitas pendidikan yang lebih unggul; kelahiran tahun 1980-2000; akrab dengan sosial media; kreatif, efisien, produktif, dan memiliki kegemaran; ingin serba cepat dan dinamis; dan pikiran terbuka (luas), kritis, dan berani (Budiati, 2018). 


\section{PEMBAHASAN}

Berdasarkan pengamatan peneliti dan literature dari berbagai penelitian ditemukan bahwa gerakan hijrah Islami milenial dapat dilakukan dengan cara melibatkan aktor dan aksi hijrah, sehingga berkaitan dengan teori gerakan sosial baru maka paradigma yang tepat dalam menganalisis gerakan hijrah Islami milenial adalah paradigma berorientasi identitas. Peneliti melakukan analisis menggunakan kelebihan dari paradigma tersebut, yaitu:

Secara umum, mendeskripsikan sebagian eskpresi kuat dari gerakan sosial baru di masyarakat modern yang banyak mengalami perubahan dalam mengungkapkan sesuatu. Fenomena hijrah islami milenial, ekspresi yang timbul adalah ekspresi kuat dalam perkembangan hijrah islami di Indonesia, diantaranya: (1) Banyaknya artis atau public figure yang melakukan hijrah seperti Laudya Cyntia Bella, Kartika Putri, Arie Untung dan masih banyak lagi, hijrah di kalangan artis disebabkan karena menginginkan kehidupan dunia yang dimilikinya bermanfaat dan bermakna dengan meningkatkan keimanan dan ketaqwaan sebagai bekal di akhirat nanti. Hijrah yang dilakukan artis atau selebritis dapat disebut micro-celebrities karena mempunyai ciri-ciri muda, muslim, berani berhijrah, dan populer. Para micro-celebrities yang memiliki kemampuan dan pengetahuan agama Islam, serta dukungan dari akun-akun media sosial yang mengatasnamakan hijrah (Annisa, 2018). (2) Maraknya hijrah islami pada milenial memberikan peluang bagi para pelaku ekonomi dalam memproduksi pakaian-pakain muslim sesuai ajaran Islam dengan menggunakan model pakaian dan warna yang sedang diminati atau tren dikalangan milenial. Hijrah online melalui media sosial dengan memanfaatkan hubungan kuasa, pihak-pihak yang merealisasikan marketing branding, dengan cara memberikan pesan komunikasi yang menarik dan efisien (Annisa, 2018). (3) Ekspresi juga terlihat pada perkembangan teknologi informasi, mudahnya akses internet pada berbagai kalangan masyarakat, hijrah semakin mudah dengan terbentuknya akun-akun sosial media yang menjelaskan tentang islam dari berbagai hal sehingga milenial yang senang dengan sosial media akan lebih tertarik dalam melakukan perubahan diri melalui konten islami yang dibaca oleh dirinya sendiri dan merenungkan nilai-nilai agama islam dengan baik, dengan dukungan motivasi yang kuat, namun yang menjadi kekhawatiran adalah perlunya penyaringan informasi pada berita palsu atau hoax apalagi yang berkaitan dengan agama, sehingga milenial perlu cerdas dalam menangkap informasi. Cara dalam menyebarkan informasi adalah melalui media sosial yang secara massif digunakan pendakwah Indonesia yang memberikan tantangan dan peluang, termasuk bagi generasi milenial sebagai pengguna mayoritas (Zulhazmi \& Hastuti, 2018). 
Ekspresi tatanan gerakan sosial baru melalui pandangan kelas dan mengurangi batasan kondisi material. Ekspresi milineal dalam hijrah islami, terlihat pada gagasan yang maju dari para milenial yang memiliki pola pikir lebih kritis dan terbuka dalam memahami, melaksanakan, mengikuti segala perintah dalam ajaran agama islam. Menurut Hasanudiin Ali dan Lilik Purwandi (2017), salah satu kelas menengah masyarakat milenial adalah yang biasa berpikir out of the box, banyak ide dan gagasan serta dengan mudah berkomunikasi yang disebabkan oleh tumbuhya industri oleh kaum muda (Walidah, 2017). Pola pikir berlandaskan agama islam akan membuat milenial lebih paham ajaran agama Islam yang mengacu pada kandungan ayat Al-Qur'an, Hadist, kisah-kisah Nabi, dengan direalisasikan pada bentuk perilaku serta lahiriah dan batiniah dalam kehidupan sehari-hari. Dalam merealisasikan ajaran agama Islam, maka milenial perlu memiliki karakter yang baik dan benar, yaitu pengetahuan tenttang moral (moral knowing), perasaan atau pengetahuan tentang emosi atau moral (moral feeling), dan perbuatan bermoral (moral action) (Muntaqo, R. \& Musfiah, 2018).

Perilaku ekspresif menjadi fokus perhatian. Perilaku ekspresif dari hijrah islami milenial diterapkan dengan cara mengikuti berbagai kajian-kajian islam yang sekarang menyebar diberbagai daerah seperti salah satunya Kota Bandung. Kota Bandung memiliki kajian islami di berbagai masjid diantaranya masjid Agung di Alun-alun, masjid Agung Trans Studio, masjid Telkom di Gerlong, Masjid Salman ITB, masjid Daarut Tauhid dan masih banyak masjid lainnya. Kajian-kajiaan islami akan disampaikan oleh para tokoh agama seperti ustadz Aam Amiruddin, ustadz Abdul Somad, ustadz Adi Hidayat, ustadz Hanan Attaki, ustadz AA Gym dan tokoh agama lainnya. Ustadz Hanan Attaki merupakan penggagas dari komunitas Pemuda Hijrah yang diisi oleh para pemuda yang ingin hijrah, awal kajian dilaksanaka di Masjid AlLathif kota Bandung Jawa barat, tujuannya mengajak para pemuda untuk berubah ke arah yang lebih baik dan kajian berisi hal-hal di kehidupan sehari-hari yang menjadi masalah para pemuda (Fatoni, U. \& Rais, 2018). Selain itu, perilaku ekspresif lainnya adalah di media sosial, para milenial muslim memberikan konten-konten islami pada jejaring sosial media yang mereka miliki agar dapat memotivasi diri sendiri maupun orang lain untuk berhijrah, dan juga terlihat dari perubahan pakaian-pakaian yang mencirikan sebagai umat islam, khusunya pada perempuan yang terlihat berpakain sesuai dengan syariat islam atau setidaknya menutup aurat, mengubah tampilan berpakain memang tidak mudah maka perlu motivasi yang kuat dalam diri individu yang menyiratkan bahwa dengan pakaian yang baik akan merubah perilakunya menjadi lebih baik dengan proses-proses yang dijalani.

Secara substantif, peran dan posisi aktor-aktor modern bersama-sama berjuang dengan sadar dalam memerangi kekuasaan sosial dalam menciptakan identitas baru dan ruang demokratis

85 | SOSIOGLOBAL : Jurnal Pemikiran dan Penelitian Sosiologi, Vol. 3, №. 2, Juni 2019 
aksi sosial yang lebih bebas. Peran dan posisi aktor milenial dalam melaksanakan hijrah tidak mudah, peran yang dapat ditunjukkan oleh milenial adalah mereka berperan sebagai muslim dan muslimah yang sesuai dengan ajaran agama islam seperti dalam kehidupan sehari-hari melaksanakan shalat, sedekah, mengaji, membantu orang lain dan ajaran islam lainnya, sehingga peran tersebut dapat menjadi identitas milenial sebagai masyarakat yang taat dengan agama islam. Selain itu, posisi yang dimiliki milenial islam adalah dengan menempatkan dirinya sebagai makhluk yang beragama islam dan taat aturan agama islam. Aksi yang dapat dilakukan oleh milenial muslim seperti mengikuti kajian-kajian islam, membantu sesama dan yang berbeda agama sehingga terbentuk toleransi, menampilkan pameran-pameran buku islam, dakwah melalui sosial media, aksi yang kurang lebih selama 2 tahun ini berjalan yaitu aksi 212, dan aksi-aksi lainnya yang mencirikan sebagai hijrah islami kaum milenial. Menurut Rahmat Aziz (2012) kepribadian ulul albab perlu memiliki empat ciri yaitu: (1) Kedalaman spiritual merupakan manusia dapat memiliki arti dan perilaku semangat beragama; (2) Keagungan akhlak adalah beriperilaku sesuai ajaran islam; (3) Keluasan ilmu yaitu kemampuan dalam menyelesaikan masalah pada bidang keahliannya; (4) Kematangan profesional yaitu mampu bekerja dan berperilaku profesianal pada ilmunya dalam menyelesaikan masalah (Munir, 2018).

Secara khusus, gerakan sosial baru meletakkan posisi pribadi sebagai kebersamaan yang bebas, manusia bebas dalam mengubah identitas dan mencari makna baru bagi identitasnya. Hijrah islami para milenial adalah menempatkan individu-individu yang hijrah islami ke arah tujuan hidup yang lebih baik dan terarah. Tujuan dilakukannya hijrah adalah dengan cara mengembangkan ilmu agama islam yang merupakan bentuk memperbaiki diri dari yang buruk menjadi baik, dari yang salah menjadi benar, bahkan dari yang haram menjadi halal. Makna yang diperoleh milenial dalam hijrah islami akan memberikan arti dalam hidup yang tidak hanya terpaku kenikmatan duniawi, tetapi dibalik itu semua terdapat "tempat tinggal abadi yaitu surga" sebagai tempat yang kekal. Hijrah mengandung tiga makna diantaranya: (1) Hijrah makaniyah (teritorial); (2) Hijrah nafsiyah yaitu pindah secara spiritual dan intelektual seperti dari kekakfiran kepada keimanan; (3) Hijrah amaliyah merupakan hijrah atau pindah secara perilaku dan perbuatan seperti meninggalkan yang dilarang dan melaksanakan yang diperintahkan oleh ajaran agama Islam (Ibrohim, 2016). Pemaknaan akan berorientasi pada agama islam, dengan melaksanakan perintah dan ajaran agama islam dari Allah swt. maka umat islam akan lebih memfokuskan diri pada ibadah, karena yakin bahwa jika hanya mencari dunia maka manusia tidak akan pernah puas dan tidak akan abadi, sedangkan tujuannya menjadi memperoleh ridho Allah swt. dan surga, maka dunia akan mengikuti, sebab segala sesuatu dari Allah swt. pasti dan selalu terbaik untuk hamba-hambanya. 
Suci Wahyu Fajriani

\section{SIMPULAN}

Hijrah islami milenial yang berkembang sangat besar di Indonesia, yang disebabkan oleh adanya keinginan individu atau kelompok untuk menjadi pribadi yang lebih baik lagi dari sisi agama Islam. Masyarakat yang melaksanakan hijrah memiliki keinginan agar hidup mereka lebih bermakna, sehingga aksi yang dilakukan beragama seperti mengikuti kajian-kajian agama islam, berpakaian sesuai syariat islam, tata cara berperilaku sesuai agama islam, dan sebagainya. Gerkana hijrah islami milenial sangat berpengaruh pada masyarakat milenial yang memang lebih mengenal media sosial, lebih kritis, lebih dapat memberdakan mana yang baik dan buruk. Milenal memiliki berbagai alasan dan cara dalam melakukan hijrah islami.

Berdasarkan gerakan sosial baru (GSB) terdapat paradigma berorientasi identitas yang dijadikan pisau analisis, yaitu: (1) Fenomena hijrah islami milenial, ekspresi yang timbul adalah ekspresi kuat dalam perkembangan hijrah islami di Indonesia pada kalangan artis, pelaku ekonomi, dan hijrah melalui media sosial. (2) Ekspresi milineal dalam hijrah islami, terlihat pada gagasan yang maju dari para milenial yang memiliki pola pikir lebih kritis dan terbuka dalam memahami, melaksanakan, mengikuti segala perintah dalam ajaran agama islam. (3) Perilaku ekspresif dari hijrah islami milenial diterapkan dengan cara mengikuti berbagai kajiankajian islam yang sekarang menyebar diberbagai daerah seperti salah satunya Kota Bandung. (4) Peran dan posisi aktor milenial dalam melaksanakan hijrah tidak mudah, peran yang dapat ditunjukkan oleh milenial adalah mereka berperan sebagai muslim dan muslimah yang sesuai dengan ajaran agama islam. (5) Hijrah islami para milenial adalah menempatkan individuindividu yang hijrah islami ke arah tujuan hidup yang lebih baik dan terarah.

\section{DAFTAR PUSTAKA}

Abdullah, S. D. A. 2018. Peran Hanan Attaki dalam Membangun Persepsi Generasi Milenial Tentang Tuhan (Analisis Isi Atas Video "Kangen" di Youtube). 7(1), 65-74.

Annisa, F. 2018. Hijrah Milenial: Antara Kesalehan dan Populism. Maarif Institute, 13(1), 38 54.

Aswadi. 2011. Refomulasi epistemologi hijrah dalam dakwah. ISLAMICA, 5(2), 158-164.

Budiati, I., Susianto, Y., Adi, W., P. (dkk). 2018. Statistik. Gender Tematik: Profil Generasi Milenial Indonesia (I. (dkk) Said, Ali., Budiati, Ed.).

Budiati, I. (dkk). 2018. Statistik Gender Tematik: Profil Generasi Milenial Indonesia (A. P. Said, A., Budiati, I., Rahayu, T. R. B., \& Raharjo, Ed.). Jakarta: (C) Kementerian Pemberdayaan Perempuan dan Perlindungan Anak.

Fatoni, U. \& Rais, A. N. 2018. Pengelolaan Kesan Da' i dalam Kegiatan Dakwah Pemuda Hijrah. Dakwah Dan Komunikasi, 12(2), 211-222.

Ghufron, A. 2017. Bab II Teori Kontekstualisasi, Hijrah, dan Jihad. 9-10. Retrieved from digilib.uinsby.ac.id.

Ibrohim, B. 2016. Memaknai momentum hijrah. Studia Didkatika Jurnal Ilmiah Pendidikan, 
$10(2), 65-74$.

Jamal, M. 2011. Konsep Al-Islam dalam Al-Qur'an. Al-Ulum, 11(2), 283-310.

James, Elizabeth, \& Hope, S. 2015. Muslim Millennial Attitudes on Religion \& Religious Leadership. Uni Emirat Arab: Zogby Research Services, LLC.

Munir, M. 2018. Membingkai Kepribadian Ulul Albab Generasi Muda. Ta'limuna, 7(1).

Muntaqo, R. \& Musfiah, A. 2018. Tradisi isra' mi'raj sebagai upaya pembentukan karakter generasi millenial. Paramurobi, 1(2), 66-78.

Nafsiyah, H., Amaliyah, H., Hijrah, N., \& Amaliyah, H. 2016. Memaknai momentum bijrah. 10(2), 65-74.

Nazir, M. 1998. Metode Penelitian. Ghalia Indonesia: Jakarta.

Raharjo, B. 2018. Fenomena Hijrah Pemuda : Membalik Stigma Muslim Milenial.

Rusmanto, J. 2018. GERAKAN SOSLAL, Sejarah Perkembangan Teori antara Kekuatan dan Kelemahan.

Sarwono, J. 2006. Metode Penelitian Kuantiatif dan Kualitatif. Yogyakarta: Graha Ilmu.

Uberman, Matan \& Shay, S. 2016. Hijrah According to the Islamic State: An Analysis of Dabiq. 8(9), 16-20. https://doi.org/10.2307/26351451.

Walidah, I. A. 2017. Tabayyun di era generasi millennial. Living Hadis, 2(1), 317-344.

Yasin, N. A. Mohd \& Azman, N. A. B. 2019. Islamic State's Online Social Movement Lifecycle: From Emergence to Repression in Southeast Asia. 11(1), 80-85. https://doi.org/10.2307/26568582.

Yuniar, R. W. 2019. Gerakan Hijrah Milenial di Tengah Pusaran Pilpres 2019 , Berpengaruh?

Zulhazmi, A. Z., \& Hastuti, D. A. S. 2018. Da'wa, Muslim Millennials and Social Media. II(2), $121-138$. 